\title{
Risk Factors for Peak Dose Dyskinesia in 100 Levodopa-treated Parkinsonian Patients
}

\author{
Pierre J. Blanchet, Pierre Allard, Laurent Grégoire, François Tardif \\ and Paul J. Bédard
}

\begin{abstract}
Background: No clinical parameter other than "sufficient" dopamine denervation and exposure to exogenous levodopa has been unquestionably linked to dyskinesia in levodopa-treated Parkinson's disease patients. Methods: We retrospectively analyzed data on 100 consecutive patients treated with levodopa for 1 to 18 years to identify clinical risk factors for dyskinesia. The cumulative dyskinesia-free survival probability in relation to levodopa therapy was assessed using the Kaplan-Meier method. Results: Overall, $56 \%$ of patients developed dyskinesia after a mean of 2.9 years, a figure similar to the average duration of levodopa treatment in the non-dyskinetic group. Dyskinetic patients were significantly younger at disease onset, but their mean latency to dyskinesia induction after levodopa initiation was not different from older dyskinetic individuals and the overall dyskinesia-free survival of younger subjects was not worse either. Dyskinetic patients were on a higher daily levodopa dose than non-dyskinetic subjects when dyskinesia emerged, but the cumulative levodopa dose used prior to dyskinesia did not discriminate dyskinetic from non-dyskinetic patients. A delay in initiating levodopa therapy of more than three years after disease onset and levodopa treatment initiation in Hoehn-Yahr stage II compared to stage I patients did not increase the probability of developing dyskinesia over time. Conclusions: Since withholding levodopa therapy did not increase the risk for dyskinesia in our patients and can delay the emergence of dyskinesia after onset of parkinsonian symptom, a trial with a dopaminomimetic agonist as initial treatment appears logical.
\end{abstract}

RÉSUMÉ: Facteurs de risque de l'apparition de dyskinésies chez 100 patients parkinsoniens traités par la lévodopa. Introduction: Le profil clinique du parkinsonien à risque de développer des dyskinésies sous L-dopa demeure controversé. Une dénervation dopaminergique et une exposition à la L-dopa "suffisantes" ne peuvent identifier les sujets susceptibles. Méthode: Par une analyse rétrospective des dossiers de 100 patients traités par la L-dopa pendant au moins un an, nous avons tenté d'identifier des facteurs de risque favorisant l'apparitiende dyskinésies. La méthode de KaplanMeier a permis de comparer la probabilité de sous-groupes de sujets de demeurer sans dyskinésie en fonction de la durée de la dopathérapie. Résultats: La proportion de sujets dyskinétiques dans cette population a atteint $56 \%$. le délai moyen d'induction de dyskinésies après le début du traitement par la L-dopa a été de 2.9 années, une valeur non discriminante car semblable à la durée moyenne de traitement de nos sujets non dyskinétiques. Les patients dyskinétiques étaient statistiquement plus jeunes au moment de l'apparition des premiers signes parkinsoniens. Toutefois, le délai d'induction de dyskinésies et la survie globale sans dyskinésie chez les sujets jeunes n'étaient pas différents de ceux des sujets plus âgés. La dose quotidienne de L-dopa administrée au moment de l'apparition de dyskinésies était en moyenne plus élevée que celle des sujets non dyskinétiques mais la dose cumulative de L-dopa avant l'apparition de dyskinésies était semblable pour les deux groupes. L'introduction de la L-dopa plus de trois ans après le début des symptômes parkinsoniens ou au stade Hoehn-Yahr Il plutôt que I n'a pas été associée à une probabilité accrue de développer des dyskinésies en cours de dopathérapie. La dyskinésie est un phénomène précoce dont le processus d'induction n'est pas accéléré par une dopathérapie introduite plus tardivement. Conclusion: Les auteurs concluent qu'il est souhaitable de tenter un traitement avec un agoniste dopaminergique dans les stades initiaux de la maladie de Parkinson afin de retarder l'apparition de dyskinésies après le début du syndrome parkinsonien, en particuler chez les sujets jeunes.

Can. J. Neurol. Sci. 1996; 23: 189-193

First described by Cotzias et al.,' peak dose dyskinesia (PDD) is the most frequent form of abnormal involuntary movements encountered in patients with Parkinson's disease treated with levodopa. PDD occurs when control of parkinsonian symptoms by levodopa is maximal. The pathophysiology of PDD is not yet understood but seems to arise from the chronic administration of exogenous levodopa in the presence of a dopaminedepleted but otherwise intact striatum. ${ }^{2}$ PDD can be reproduced in the 1-methyl-4-phenyl-1,2,3,6-tetrahydropyridine (MPTP)- induced primate model of parkinsonism following standard levodopa therapy for only 4-8 weeks. ${ }^{3-4}$. Electrophysiological $^{5}$ and regional metabolic brain mapping ${ }^{6}$ studies in

From the Neurobiology Research Centre, Hôpital de l’Enfiant-Jésus (P.J.B., L.G., F.T. P.J.B.) Canada; and Epidemiology Research Unit. Hôpital du Saint-Sacrement (P.A.) Québec City (Québec), Canada.

RECEIVED JULY 13, 1995. ACCEYTED IN FINAL FORM MARCH 5, 1996.

Reprim requests to: Dr. Paul J. Bédard, Neurobiology Research Centre, Hôpital de l'Enfant-Jésus, 140I, 18e Rue, Québec City (Québec). Canada GIJ IZA 
primates have underscored the crucial role played by the overactivity of the globus pallidus pars lateralis neurons during PDD. This neuronal overactivity results in excessive inhibition of the subthalamic nucleus, a possible common denominator for various hyperkinesias. ${ }^{7}$

From a clinical standpoint, several studies have tried to identify risk factors for PDD, but agreement on any of these has yet to be reached. A young age at the onset of Parkinson's disease is regarded as a risk factor in most studies ${ }^{8-14}$ but others disagree. ${ }^{15-16}$ The severity of the disease at the initiation of levodopa treatment is also viewed as a highly significant risk factor for dyskinesia. ${ }^{16-20}$ The exact contribution of the total duration of the disease and duration of levodopa treatment is more controversial, leading to uncertainties regarding the "optimal" delay of initiation of levodopa in Parkinson's disease. Some authors have suggested that patients in whom levodopa therapy was initiated early after disease onset were less susceptible to dyskinesias $^{10.13,19}$ but Hoehn ${ }^{21}$ contended that the frequency of dyskinesias did not vary with the delay in initiation of levodopa. Several studies ${ }^{8,15,16.22}$ have found no relationship between dyskinesia and duration of levodopa therapy whilst others have. ${ }^{23-25}$ Such a relationship is important to document because it supports the decision to delay levodopa initiation. The optimal dose of levodopa to administer has also been debated but a chronic lowdose regimen has been linked to a lower incidence of dyskinesia. ${ }^{25,26}$ Furthermore, a higher cumulative dose of levodopa was found to discriminate dyskinetic from non-dyskinetic patients treated for a similar length of time. ${ }^{27}$

Since levodopa remains, 25 years after its introduction in clinical practice, the most effective antiparkinsonian treatment, the identification of a clearer risk profile for PDD is important to help understand its basis and could prevent its early development. Thus, we completed a retrospective analysis in a consecutive case series of 100 patients treated between 1973 and 1991.

\section{Patients and Methods}

Study patients were identified amongst 131 patients included in our Movement Disorders Clinic databank in July 1991. We included patients with idiopathic Parkinson's disease only, defined as a clinical syndrome of unknown cause characterized by at least two of the following features: bradykinesia, rigidity and resting tremor. A total of 100 patients met the following criteria: oral levodopa treatment (combined with a peripheral decarboxylase inhibitor) initiated by our group for a duration of at least one year, with the records of at least two follow-up visits. Levodopa was usually initiated in a context of sufficient subjective limitations in activities of daily living or an inability to perform at work that threatened job security. During follow-up, patients were assessed on an outpatient basis to confirm the diagnosis of Parkinson's disease and document the presence or absence of PDD. They were asked specifically whether or not they had experienced dyskinesia since the last visit. Drug regimen was adjusted individually. The time of emergence of PDD during follow-up could be estimated with an accuracy of six months or less. Diphasic dyskinesia and off-period dystonia are not included in the analysis.

Patients who developed PDD were compared to those who did not along the following parameters: (1) gender, (2) age at disease onset, (3) Hoehn-Yahr stage at levodopa initiation, (4) disease duration, (5) duration of levodopa treatment, (6) cumulative levodopa dose over the study period. The delay (latency) of induction of PDD was given by the time interval between levodopa initiation and the first documentation of PDD.

The Kaplan-Meier survival analysis method ${ }^{28}$ was used to assess the cumulative probability of not reaching the end-point (PDD) during levodopa treatment for different criteria: (1) age at disease onset ( $\leq 60$ years), (2) delay of levodopa initiation after disease onset ( $<3$; $\geq 3$ years), (3) Hoehn-Yahr stage at levodopa initiation (I versus II-III). Survival plots data were compared using the Wilcoxon and log-rank tests.

Parameters used to discriminate dyskinetic from non-dyskinetic patients are given as means and standard errors, and compared by performing a one-way analysis of variance with unpaired $\mathrm{t}$-tests.

\section{ResUlTS}

The percentage of patients who developed dyskinesia are given in Table 1 according to baseline characteristics. Twentynine of the 44 women $(65.9 \%)$ and 27 of the 56 men (48.2\%) under study developed PDD. Compared to older individuals, patients 40 years of age and younger at disease onset became more frequently dyskinetic. Patients in Hoehn-Yahr stages I and II at levodopa initiation were equally represented in both dyskinetic and non-dyskinetic groups. The disease duration prior to levodopa initiation was not associated with a higher percentage of dyskinetic patients.

As a whole, patients with PDD were significantly younger at disease onset than non-dyskinetic patients (51.0 vs. 59.9 years;

Table 1. Percentage of patients with dyskinesia by baseline characteristics.

\begin{tabular}{lccc}
\hline & Variable & $\begin{array}{c}\text { Number of } \\
\text { patients }\end{array}$ & $\begin{array}{c}\text { Percentage } \\
\text { with dyskinesia }\end{array}$ \\
\hline Sex & & & \\
& Female & 44 & 65.9 \\
& Male & 56 & 48.2 \\
\hline Age at disease onset & & & \\
(yrs) & 540 & & \\
& $41-50$ & 14 & 71.4 \\
& $51-60$ & 20 & 80.0 \\
& $>60$ & 31 & 61.3 \\
& & 35 & 31.4 \\
\hline
\end{tabular}

Hoehn-Yahr stage at

levodopa initiation

\begin{tabular}{rrr} 
I & 50 & 56.0 \\
II & 47 & 55.3 \\
III & 3 & 66.7 \\
\hline
\end{tabular}

Disease duration prior

to levodopa

initiation

(yrs)

\begin{tabular}{lll}
$<3$ & 65 & 53.8 \\
$\geq 3$ & 35 & 60.0 \\
\hline
\end{tabular}


Table 2. Summary of potential risk factors in relation to the absence or presence of dyskinesia.

\begin{tabular}{|c|c|c|c|c|c|}
\hline \multirow{2}{*}{ Variable } & \multicolumn{2}{|c|}{ Non-dyskinetic } & \multicolumn{3}{|c|}{ s Dyskinetics } \\
\hline & Mean & SEM $^{*}$ & Mean & SEM $^{*}$ & P-Value \\
\hline Age at disease onset (yrs) & 59.9 & 1.6 & 51.0 & 1.4 & $<.0001$ \\
\hline $\begin{array}{l}\text { Hoehn-Yahr stage at levodopa } \\
\text { initiation }\end{array}$ & 1.5 & 0.1 & 1.5 & 0.1 & .9 \\
\hline Disease duration prior to levod & & & & & \\
\hline initiation (yrs) & 2.2 & 0.3 & 2.7 & 0.3 & .2 \\
\hline Total disease duration (yrs) & 5.7 & 0.5 & 10.8 & 0.7 & $<.0001$ \\
\hline $\begin{array}{l}\text { Disease duration free of } \\
\text { dyskinesia (yrs) }\end{array}$ & 5.7 & 0.5 & 5.5 & 0.5 & .79 \\
\hline Total levodopa treatment (yrs) & 3.7 & 0.4 & 8.4 & 0.6 & $<.0001$ \\
\hline $\begin{array}{l}\text { Levodopa treatment free of } \\
\text { dyskinesia (yrs) }\end{array}$ & 3.7 & 0.4 & 2.9 & 0.4 & .20 \\
\hline $\begin{array}{l}\text { Daily levodopa dose at emerge } \\
\text { of dyskinesia (for dyskinetics } \\
\text { or at last follow-up } \\
\text { (for non-dyskinetics) (mg) }\end{array}$ & 309.1 & 15.1 & 455.4 & 29.1 & $<.0001$ \\
\hline $\begin{array}{l}\text { Cumulative levodopa dose ove } \\
\text { the time interval free of } \\
\text { dyskinesia (grams) }\end{array}$ & 458.4 & 81.5 & 391.8 & 68.9 & .53 \\
\hline
\end{tabular}

$\mathrm{p}<0.0001$ ) (Table 2). Whilst the total duration of the disease and levodopa treatment was significantly longer in patients with PDD $(10.8 \pm 0.7$ versus $5.7 \pm 0.5$ years; $p<0.0001)$, the duration of the disease $(p=0.79)$ and levodopa treatment free of dyskinesia $(p=0.20)$ were similar between the two groups of patients (Table 2), for a mean latency to dyskinesia onset of 2.9 years (range 3 months to 17 years). Although patients 40 years of age and younger at disease onset had levodopa initiated significantly later than patients older than $60(4.3 \pm 0.7$ versus $1.7 \pm 0.2$ years; $p<0.0001$ ), the average time spent on levodopa up to the emergence of dyskinesia was similar between these two groups $(2.3 \pm 0.4$ versus $1.9 \pm 0.6$ years; $p=0.63)$ (data not shown). The mean Hoehn-Yahr stage at levodopa initiation and mean disease duration prior to levodopa initiation did not discriminate dyskinetic from non-dyskinetic individuals (Table 2). The daily levodopa dose administered to patients when PDD was first documented was significantly higher than for non-dyskinetic subjects at their last follow-up visit $(455.4 \pm 29.1$ versus $309.1 \pm$ $15.1 \mathrm{mg}$, respectively).

The dyskinesia-free survival between patients over age 60 at disease onset and those aged 60 years-old or less was assessed using the Kaplan-Meier method, and the apparent difference observed between these two groups failed to reach statistical significance (Figure 2). A delayed initiation of levodopa by three years or more after disease onset did not influence the dyskinesia-free survival compared to patients initiating levodopa earlier (Figure 3). Similarly, the dyskinesia-free survival was similar between patients in stages I and II at treatment onset, the

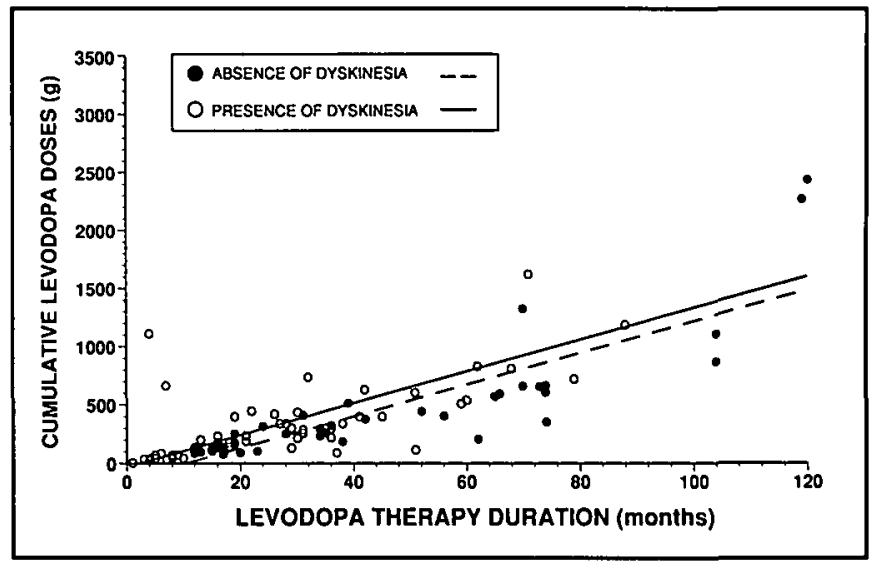

Figure 1: Cumulative levodopa doses in relation to the levodopa treatment interval free of dyskinesia in patients with (०) or without (•) dyskinesia.

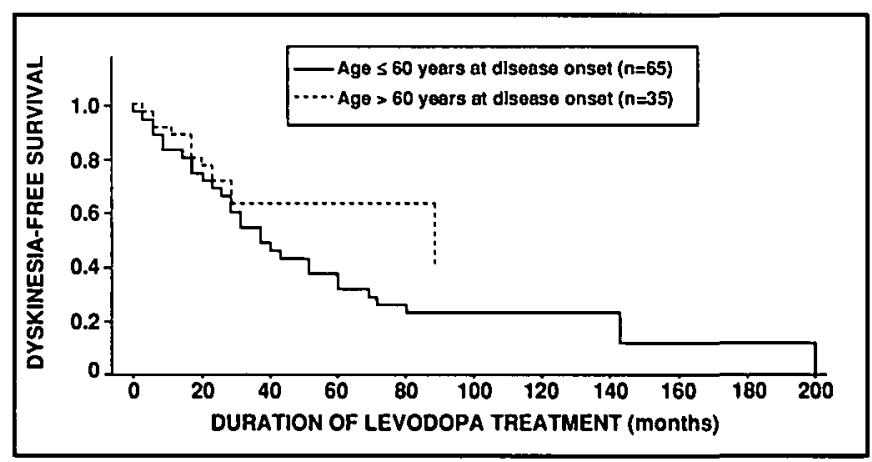

Figure 2: Cumulative probability of remaining free of dyskinesia in 100 patients according to age at disease onset.

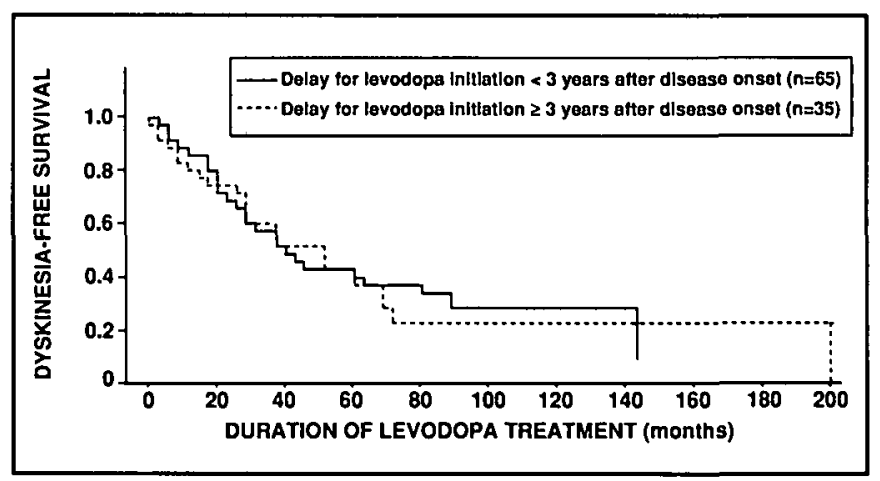

Figure 3: Cumulative probability of remaining free of dyskinesia in 100 patients according to levodopa initiation delay after disease onser.

very small number of patients beyond stage II at levodopa initiation ( $\mathrm{N}=3$ ) precluding an extension of this result to patients with moderately severe disease (Figure 4). Sex was not linked to the probability of developing PDD (data not shown).

The dyskinetic patients were equally distributed between those who developed PDD after a relatively short (within the first two years; $\mathrm{N}=27$ ) or longer (more than two years; $\mathrm{N}=29$ ) latency following levodopa initiation. No single factor was found to increase the proneness to develop early dyskinesia 


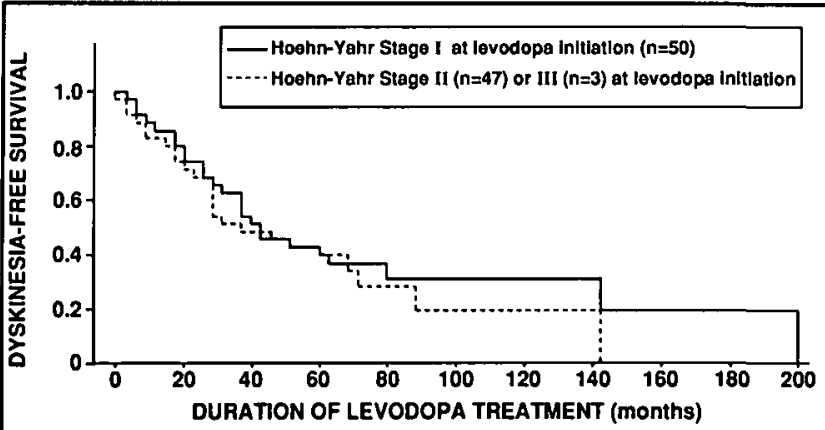

Figure 4: Cumulative probability of remaining free of dyskinesia in 100 patients according to the Hoehn-Yahr stage of Parkinson's disease at levodopa initiation.

since these patients showed a mean age at disease onset $(53.4 \pm$ 2.0 versus $48.8 \pm 1.8$ years; $p=0.09$ ), mean disease duration prior to levodopa initiation $(2.7 \pm 0.4$ versus $2.6 \pm 0.5$ years; $\mathrm{p}=0.84)$ and mean Hoehn-Yahr stage at levodopa initiation ( 1.6 \pm 0.1 versus $1.5 \pm 0.1 ; \mathrm{p}=0.47$ ) essentially similar to patients with the longer latency for dyskinesia induction. The respective cumulative levodopa dose up to the appearance of PDD was expectedly different between these two dyskinetic groups (188.7 \pm 47.2 versus $587 \pm 116.7$ grams; $p<0.005$ ), an indication that no specific cumulative levodopa dose threshold underlies PDD (Figure 1).

Finally, because our patients were accrued over a long time period with changing treatment strategies, we divided them in 3 groups according to the year levodopa was initiated. The number of patients who started taking levodopa between 1973-1978, 1979-1984 and 1985-1990, and the proportion of dyskinetic patients in each group (in parentheses) were, respectively, 13 $(100 \%), 25(72 \%)$ and $62(40 \%)$. Only 3 patients developed PDD after more than 10 years of exposure to levodopa, and all those had initiated levodopa between 1973-1978, raising the possibility that they may have had PDD earlier that was missed. Excluding these 3 unusual "outliers", the median latency of induction of PDD after starting levodopa between 1973-1978, 1979-1984 and 1985-1990 was 27, 19.5 and 21 months, respectively.

\section{Discussion}

In this retrospective case series, the proportion of levodopatreated parkinsonian patients presenting PDD was $56 \%$. The probability of developing PDD once levodopa was initiated increased progressively over time, but PDD appeared relatively early on average (2.9 years) in the dyskinetic group, as observed by Horstink et al. ${ }^{16}$ and Montastruc et al. ${ }^{29}$ Moreover, the duration of the dyskinesia-free interval spent on levodopa treatment was similar in patients with or without PDD. Even though the proportion of PDD was higher in individuals with young onset disease, ${ }^{12,14}$ the decrease in dyskinesia-free survival evolved in parallel when patients aged 60 or less were compared to patients aged more than 60 at disease onset (Figure 2). In addition, the latency of appearance of PDD after levodopa initiation did not significantly differ between younger ( $\leq 40$ years) and older $(>60$ years) patients at disease onset, as reported by Peppe et al..$^{30}$ (data not shown). Thus, PDD commonly arises as an early com- plication of levodopa therapy and its latency of induction does not differ between age groups.

Another critical factor pertaining to dyskinesia induction is the delay of levodopa initiation after onset of parkinsonian symptoms. Indeed, the optimal timing of initiation of levodopa is controversial and many advise that a levodopa therapy be delayed as long as possible. ${ }^{31.32}$ Other studies ${ }^{13,19.20}$ have found that patients in whom levodopa was initiated late developed PDD sooner, raising the suspicion that severity of disease at levodopa initiation is a more significant risk factor for PDD than duration of levodopa treatment itself. In our case series, the mean delay of levodopa initiation for dyskinetic and non-dyskinetic patients was not found to differ and a delay of three years or more in levodopa initiation did not worsen the long-term susceptibility to dyskinesia compared to an earlier initiation (Figure 3 ), as suggested by Hoehn. ${ }^{21}$ In addition, our younger patients ( $\leq 40$ years at disease onset) had levodopa initiated significantly later than older patients (over age 60) but this did not seem to adversely affect the latency of dyskinesia induction which was not significantly different in these two groups (see Results). These results are similar to these obtained by Peppe et al. ${ }^{30}$ Likewise, Quinn et al. ${ }^{12}$ were not able to correlate the onset of dyskinesia with a specific delay in levodopa initiation in their young onset patients.

Similar to Peppe et al. ${ }^{30}$ we found patients in stage I and II at levodopa initiation not to differ in terms of their dyskinesia-free survival over time (Figure 4). Admittedly, a greater number of stage III patients could have produced a very different picture. It is well known that humans ${ }^{18}$ and primates ${ }^{33}$ with severe MPTPinduced parkinsonism (equivalent to stage III-V) develop dyskinesia early after levodopa initiation in a very high proportion of cases. In our study, the relation between a higher daily levodopa dose and PDD (Table 2) could tentatively be explained by a more severe underlying parkinsonian syndrome in these patients or represent a levodopa "toxic" effect. However, the cumulative dose administered during the dyskinesia-free time spent on levodopa (Table 2 and Figure 1) was similar between patients with or without PDD and the cumulative threshold dose for PDD varied greatly amongst dyskinetic individuals (Table 2), suggesting that dyskinesia emergence is not tightly dose-related. Other studies ${ }^{14,30-34}$ have not found a relationship between dyskinesia and levodopa dose. As mentioned earlier, patients in the dyskinetic group were also relying more on levodopa for optimal relief. Obviously, a prospective study would be needed to study the relationship between disease severity, rate of disease progression and dyskinesia onset whilst controlling for concomitant medications.

In this retrospective study, younger patients at disease onset more frequently developed dyskinesia, but their dyskinesia-free survival was similar to older patients. Peak dose dyskinesia appeared early on average (in the first three years of levodopa intake) and within the limits of our retrospective data, a delay in levodopa initiation by at least three years and the stage of the disease (I versus II) at levodopa initiation did not worsen the risk for dyskinesia. Taken together, the results of this study, as well as of Peppe et al., ${ }^{30}$ indicate that a certain proportion of parkinsonian patients are susceptible of developing dyskinesia. Apart from perhaps a young age at disease onset, no single factor accounts for the risk of developing dyskinesia. In this population at risk, once levodopa is initiated, the appearance of dyskinesia can be expected after an average interval of three 
years, which seems independent of any other risk factor. It follows that withholding levodopa therapy would delay the total period free of dyskinesia from disease onset. Withholding levodopa might entail unacceptable disability. In a recent randomised, controlled study, ${ }^{29}$ levodopa initiation following a course of bromocriptine monotherapy was delayed by an average of 2.7 years but once levodopa was initiated, motor complications (including dyskinesia) arose after a mean latency of 2.2 years, a figure comparable to that reported in their patients treated firsthand with levodopa and to ours. In fact, in spite of considerable changes in treatment strategies between 1973 and 1990, the median latency of onset of PDD after levodopa initiation continues to be consistently short in "susceptible" individuals, even today. Since bromocriptine monotherapy is seldom responsible for the emergence of $\mathrm{PDD}$, such a strategy significantly delayed the onset of PDD after parkinsonian symptom onset, allowed the use of a lower daily dose of levodopa and overall improved the short-term survival for PDD. ${ }^{29}$ Thus, we conclude that an initial trial of dopaminomimetic agonist therapy is reasonable and should be continued as long as the patient can tolerate it to postpone the emergence of dyskinesia after parkinsonian symptom onset and reduce levodopa daily dose once the latter drug is added. Further randomized controlled trials with adequate numbers of untreated patients, comparing treatment initiation with levodopa or a dopamine agonist and characterizing disease severity and progression in a detailed fashion are warranted.

\section{ACKNOWLEDgements}

The authors thank Gilles Grenon and Alain Turgeon for their help in shaping the computer database. Diane Potvin was involved in the statistical analysis. Monique Baron prepared the manuscript. Pierre Blanchet was funded by the Fonds de la Recherche en Santé du Québec. This work was presented in part at the Second International Congress of Movement Disorders, Munich, Germany, June 24-26, 1992.

\section{REFERENCES}

1. Cotzias GC, Van Woert MH, Schiffer LM. Aromatic amino acids and modification of parkinsonism. N Engl J Med 1967; 276: 374-379.

2. Nutt JG. Levodopa-induced dyskinesia: Review, observations, and speculations. Neurology 1990; 40: 340-345.

3. Crossman AR, Clarke CE, Boyce S, Robertson RG, Sambrook MA. MPTP-induced parkinsonism in the monkey: neurochemical pathology, complications of treatment and pathophysiological mechanisms. Can J Neurol Sci 1987; 14: 428-435.

4. Bédard PJ, Gomez-Mancilla B, Blanchette P, et al. Levodopa-induced dyskinesia: facts and fancy. What does the MPTP monkey model tell us? Can J Neurol Sci 1992; 19: 134-137.

5. Filion M, Tremblay L, Bédard PJ. Effects of dopamine agonists on the spontaneous activity of globus pallidus neurons in monkeys with MPTP-induced parkinsonism. Brain Res 1991; 547: 152-161.

6. Mitchell IJ, Boyce S, Sambrook MA, Crossman AR. A 2-deoxyglucose study of the effects of dopamine agonists on the parkinsonian primate brain: implications for the neural mechanisms that mediate dopamine agonists-induced dyskinesia. Brain 1992; 115: 809-824.

7. Crossman AR. A hypothesis on the pathophysiological mechanisms that underlie levodopa-or dopamine agonist-induced dyskinesia in Parkinson's disease: implications for future strategies in treatment. Mov Disord 1990; 5: 100-108.

8. Lesser RP, Fahn S, Snider SR, et al. Analysis of the clinical problems in parkinsonisms and the complications of long-term levodopa therapy. Neurology 1979; 29: 1253-1260.

9. Pederzoli M, Girotti F, Scigliano G, et al. L-Dopa long-term treatment in Parkinson's disease: age-related side effects. Neurology 1983; 33: $1518-1522$.

10. Friedman A. Levodopa-induced dyskinesia: clinical observations. J Neurol 1985; 232: 29-31.
11. Tanner CM, Kinori I, Goetz CG, et al. Age at onset and clinical outcome in idiopathic Parkinson's disease. Neurology 1985; 35 (Suppl. 1): 276

12. Quinn N, Critchley P, Marsden CD. Young onset Parkinson's disease. Mov Disord 1987; 2: 73-91.

13. Cedarbaum JM, Gandy SE, McDowell FH. "Early" initiation of levodopa treatment does not promote the development of motor response fluctuations, dyskinesias, or dementia in Parkinson's disease. Neurology 1991; 41: 622-629.

14. Wu RM, Chiu HC, Wang M, Chen RC. Risk factors on the occurrence of response fluctuations and dyskinesias in Parkinson's disease. J Neural Transm [P-D Sect] 1993; 5: 127-133.

15. Diamond SG, Markham CH, Hoehn MM, et al. Effect of age at onset on progression and mortality in Parkinson's disease. Neurology 1989; 39: 1187-1190.

16. Horstink MWIM, Zijlmans JCM, Pasman JW, et al. Severity of Parkinson's disease is a risk factor for peak-dose dyskinesia. J Neurol Neurosurg Psychiatry 1990; 53: 224-226.

17. Lang AE, Meadows JC, Parkes JD, Marsden CD. Early onset of the "on-off" phenomenon in children with symptomatic parkinsonism. J Neurol Neurosurg Psychiatry 1982; 45: 823-825.

18. Langston JW, Ballard P. Parkinsonism induced by 1-methyl-4-phenyl1,2,3,6-tetrahydropyridine (MPTP): implications for treatment and the pathogenesis of Parkinson's disease. Can J Neurol Sci 1984; II (Suppl.): 160-165.

19. Bergmann KJ, Mendoza MR, Yahr MD. Parkinson's disease and longterm levodopa therapy. In: Yahr MD, Bergmann KJ, eds. Advances in Neurology, Vol 45: Parkinson's disease. New York: Raven Press, 1986: 463-467.

20. Blin J, Bonnet AM, Agid Y. Does levodopa aggravate Parkinson's disease? Neurology 1988; 38: 1410-1416.

21. Hoehn MMM. Result of chronic levodopa therapy and its modification by bromocriptine in Parkinson's disease. Acta Neurol Scand 1985; 71: $97-106$.

22. Fahn S, Bressman SB. Should levodopa therapy for parkinsonism be started early or late? Evidence against early treatment. Can J Neurol Sci 1984; 11 (Suppl.): 200-206.

23. Klawans HL, Crossett P, Dana N. Effect of chronic amphetamine exposure on stereotyped behavior: implications for pathogenesis of L-Dopa-induced dyskinesias. In: Calne DB, Chase TN, Barbeau A, eds. Advances in Neurology, Vol. 9. New York: Raven Press, 1975: 105-112.

24. Sweet, RD, McDowell FH. Five years' treatment of Parkinson's disease with levodopa. Ann Intern Med 1975: 83: 456-463.

25. Rajput AH, Stern W, Laverty WH. Chronic low-dose levodopa therapy in Parkinson's disease: an argument for delaying levodopa therapy. Neurology 1984; 34: 991-996.

26. Poewe WH, Lees AJ, Stern GM. Low-dose L-Dopa therapy in Parkinson's disease: a 6-year follow-up study. Neurology 1986: 36: 1528-1530.

27. Tanner CM. Drug-induced movement disorders (tardive dyskinesia and dopa-induced dyskinesia). In: Vinken PJ, Bruyn GW, Klawans HL. eds. Handbook of Clinical Neurology, Vol 5(49): Extrapyramidal Disorders. Amsterdam: Elsevier Science, 1986: 185-204.

28. Lawless JF. Statistical Models and Methods for Lifetime Data. New York: J Wiley \& Sons, Eds, 1982.

29. Montastruc JL, Rascol O, Senard JM, Rascol A. A randomised controlled study comparing bromocriptine to which levodopa was later added, with levodopa alone in previously untreated patients with Parkinson's disease: a five year follow up. J Neurol Neurosurg Psychiatry 1994; 57: 1034-1038.

30. Peppe A, Dambrosia JM, Chase TN. Risk factors for motor response complications in L-Dopa-treated parkinsonian patients. In: Narabayashi $H$, Nagatsu T, Yanagisawa N, Mizuno $Y$, eds. Advances in Neurology, Vol 60: Parkinson's disease: from Basic Research to Treatment. New York: Raven Press, 1993: 698-702.

31. Fahn S, Bressman SB. Should levodopa therapy for parkinsonism be started early or late? Evidence against early treatment. Can J Neurol Sci 1984; 11: 200-206.

32. Rajput AH, Uitti RJ. When to use levodopa in parkinsonism. Lancet 1986: I(8493): 1324-1325.

33. Schneider JS. Levodopa-induced dyskinesias in parkinsonian monkeys: relationship to extent of nigrostriatal damage. Pharmacol Biochem Behav 1989; 34: 193-196.

34. Wilson JA, Smith RG. The prevalence and aetiology of long-term LDopa side-effects in elderly parkinsonian patients. Age and Ageing 1989; 18: 11-16. 